\title{
Electrochemical Behavior of Biomedical Titanium Alloys Coated with Diamond Carbon in Hanks' Solution
}

\author{
S. Gnanavel, S. Ponnusamy, L. Mohan, R. Radhika, C. Muthamizhchelvan, and K. Ramasubramanian
}

\author{
(Submitted May 18, 2017; in revised form November 24, 2017; published online March 8, 2018)
}

\begin{abstract}
Biomedical implants in the knee and hip are frequent failures because of corrosion and stress on the joints. To solve this important problem, metal implants can be coated with diamond carbon, and this coating plays a critical role in providing an increased resistance to implants toward corrosion. In this study, we have employed diamond carbon coating over Ti-6Al-4V and Ti-13Nb-13Zr alloys using hot filament chemical vapor deposition method which is well-established coating process that significantly improves the resistance toward corrosion, wears and hardness. The diamond carbon-coated Ti-13Nb-13Zr alloy showed an increased microhardness in the range of $850 \mathrm{HV}$. Electrochemical impedance spectroscopy and polarization studies in SBF solution (simulated body fluid solution) were carried out to understand the in vitro behavior of uncoated as well as coated titanium alloys. The experimental results showed that the corrosion resistance of Ti-13Nb-13Zr alloy is relatively higher when compared with diamond carbon-coated Ti-6Al-4V alloys due to the presence of $\beta$ phase in the Ti-13Nb-13Zr alloy. Electrochemical impedance results showed that the diamond carbon-coated alloys behave as an ideal capacitor in the body fluid solution. Moreover, the stability in mechanical properties during the corrosion process was maintained for diamond carbon-coated titanium alloys.
\end{abstract}

Keywords corrosion, diamond carbon, electrochemical impedance, HFCVD, titanium alloys

\section{Introduction}

Orthopedic implants like hip and knee joint replacements are important to clinicians. Before 2030, the enthusiasm of knee and hip joint replacement system is foreseen to create by 674 and $172 \%$ independently, in the USA alone (Ref 1). Inferable from these requests, the life hope of the implants is of vital significance and anticipated that would serve for a more extended period. Now, the industrial metallic materials are utilized for the orthopedic implants (titanium alloys, $\mathrm{Co}-\mathrm{Cr}$ compounds and $316 \mathrm{~L}$ stainless steel-based combinations) and fail within 16-24 years which thus prompts amendment surgery. In 2030, knee and hip replacement update operation would rely upon an increment of $135 \%$ and $600 \%$, respectively. Therefore, it is highly necessary to increase the corrosion and mechanical properties of an implant by coating. If that happened, the patient would stay away with unwanted pain from the correction surgery (Ref 2-4).

The primary purpose behind the failure of implants is due to the generation wear fragments and metal molecule release from the bearing surface during the wear and corrosion process

S. Gnanavel, Department of Biomedical Engineering, SRM Institute of Science and Technology, Chennai, Tamilnadu, India; S. Ponnusamy and C. Muthamizhchelvan, Centre for Materials Science and Nano Devices, SRM Institute of Science and Technology, Chennai, Tamilnadu, India; L. Mohan, Surface Engineering Division, CSIR-National Aerospace Laboratories, Bangalore, India; and R. Radhika and K. Ramasubramanian, Nano Functional Materials Technology Centre, Indian Institute of Technology Madras, Chennai, India. Contact e-mails: gnanambe06@gmail.com and suruponnus@gmail.com. which in turn induces osteolysis and results in aseptic discharging of orthopedic implants (Ref 5). It is seen that articulating movement of hip and knee replacement affects the sliding contact in a corrosive biological environment, hence by making the implant subjected to corrosion and wear resistance simultaneously. It is essential to say that titanium alloys have good corrosion resistance; however, under the stress and strain effect, they show the corrosion rates (Ref 6). Yan et al. (Ref 7) showed that 20-30\% material loss in Co-Cr alloys was due to the corrosion mechanism which is generally reacted in the hip implant (femoral head).

$\alpha-\beta$ and near- $\beta$ titanium alloys found the wide applications in biomedical implants in both load bearing and non-load bearing joints, due to their superior mechanical strength and excellent biocompatibility (Ref 8 ). The titanium alloys utilized as implants are reasonable because it is nontoxic and does not allow any opposite reaction in the biological tissue (Ref 9). At room temperature conditions, titanium combinations are classified as $\alpha$, near $\alpha, \alpha+\beta$, metastable $\beta$ and near $\beta$. Among the various $\beta$ combinations, near- $\beta$ alloy Ti-13Nb-13Zr is found to be more appropriate for implant work because of less elastic modulus and contains the simple combination of the elements such as $\mathrm{Zr}$ and $\mathrm{Nb}$ (Ref 10). Furthermore, Ti-6Al-4V was mostly used for artificial bone joints replacements because of its high hardness. Unlike chemical reactions, corrosion of the metal implants results in the degradation of implants. Thus, the degradation of implants due to corrosion may cause a local inflammatory response, and it may lead to the following: cessation of bone formation, synovitis and detachment of artificial implants (Ref 11).

On the other hand, the low wear resistance of implants induces the wear debris formation. There may be several reactions to occur in tissues due to the small wear resistance which leads to increase the possibility of implants failure. Thus, the mechanical properties of implants are highly relevant, and it depends on material volume and its surface characteristics (Ref 
12, 13). To prevent the corrosion of metallic implant and improve the bioactivity, there is a need for proper surface modification of metallic implants which can be achieved through the deposition of various functional coating materials. To promote the corrosion and wear resistance of implants, two ways are usually followed, such as (1) "bulk alloying', and (2) "surface modification." In this study, we have focused on surface modification of implants to solve the aforementioned problems for the biological implant applications (Ref 14). There are various metal implant surface modification techniques reported in the literature; among them, surface modification using "diamond carbon-coated" called DCC is found to be an excellent method because of its good mechanical properties (high hardness), chemical, biological inertness and makes it suitable for biomedical implant application (Ref 15, 16). DCC has also shown promising outcomes as a hemocompatible material (Ref 17-19). Various studies reported that the DCC is a biocompatible material which is a good alternative to existing materials used in biomedical implants (Ref 20-22). However, to the best of our knowledge, until now there are no studies reported on the corrosion behavior of the DCC on specifying an exact combination of titanium alloys.

In this work, Ti-6Al-4V and Ti-13Nb-13Zr alloys were selected for the investigation. Ti-6Al-4V is $\alpha+\beta$ alloy type which possesses excellent resistance toward corrosion and provides a unique biocompatibility. Moreover, it is still under the investigation because of the hazardous nature of vanadium. Ti-13Nb-13Zr is near- $\beta$-type titanium alloy which has low modulus and good biocompatibility, as well as approved by Food and Drug Administration (FDA), USA. Besides, it was found that the titanium compounds offer great grip diamond (Ref 23). Hot filament chemical vapor deposition (HFCVD) is a standout among the most generally perceived methods for the deposition of diamond carbon on the different substrate and furthermore easy to create uniform precious diamond carbon coating over a large surface (Ref 24$)$. In this present work, the corrosion and the electrical impedance characteristics of DCC on Ti-6Al-4V (ASTM grade 5) and Ti-13Nb-13Zr (ASTM F1713-08) are examined in detail.

\section{Materials and Methods}

\subsection{Sample Preparation}

Initially, a test sample of titanium alloys of $2 \mathrm{~mm}$ thickness was cut into regular square-shaped pieces $(10 \mathrm{~mm} \times 10 \mathrm{~mm})$. The cut pieces were grounded using silicon carbide paper with the range of 200-1600\# grits and polished with the use of diamond paste (0.4 microns). The polished samples were placed in an ultrasonicator and cleaned with ethanol followed by the $\mathrm{HNO}_{3}$ (nitric acid) treatment for $5 \mathrm{~min}$ to remove the oxide layer present over the substrate (titanium alloys).

\subsection{Deposition System}

Before diamond deposition, the substrates were seeded with diamond nanoparticle ( $\sim 6 \mathrm{~nm}$ diameter), dispersed in dimethyl sulfoxide (DMSO), using ultrasonicator for $30 \mathrm{~min}$. The titanium substrates again cleaned with ethanol in an ultrasonicator for $2 \mathrm{~min}$. The samples were placed in the cold walled aluminum chamber of HFCVD systems (SP3 diamond technology, USA). An array of parallel wires of $(0.12 \mathrm{~mm})$ diameter filaments with 12-mm wire-to-wire spacing and standoff distance $19 \mathrm{~mm}$ was placed above the samples. The HFCVD chamber pressure was controlled using throttle valve connected to the rotary pump. Flow rates of the precursor gases such as $\mathrm{CH}_{4}(45 \mathrm{sccm})$ and $\mathrm{H}_{2}(2250 \mathrm{sccm})$ were maintained by mass flow controller in the range of 10-90\% accuracy (MKS Instrument, USA). The chamber pressure during the deposition was set to 10 Torr and controlled by a throttle valve connected to a rotary pump. A two-color optical pyrometer was used to monitor the tungsten filament temperature $\left(\sim 2200{ }^{\circ} \mathrm{C}\right)$. The substrates temperature was measured using K-type thermocouple located at the bottom of the titanium substrates. The substrates were found to be $800{ }^{\circ} \mathrm{C}$. The whole deposition process was performed for $2 \mathrm{~h}$, and the coating thickness of the film estimated to be $\sim 1 \mu \mathrm{m}(\operatorname{Ref} 25)$.

\subsection{Characterization Technique}

The surface morphological experiments were carried out using field emission scanning electron microscopy (FESEM) supplied by Carl Zeiss, Germany supra 40VP FESEM. Buehler micro-Vickers's hardness tester was used to measure the microhardness of the substrate. Nd: YAG laser source with the wavelength of $532 \mathrm{~nm}$ used for Raman analysis supplied by LABRUM 010, UK. The topographical study was carried out using atomic force microscopy (AFM) with Easy scan2 supplied by Nanosurf, Switzerland.

\subsection{Electrochemical Measurement}

CHI604D electrochemical workstation provided by $\mathrm{CH}$ Instruments, USA, was used for electrochemical studies on substrates and coated samples. The chemical composition of SBF is tabulated in Table 1. The pH of SBF solution (7.2-7.5) was balanced by one molar hydrochloric acid solution. The test was carried out in $400 \mathrm{ml}$ of SBF solution at $36 \pm 1{ }^{\circ} \mathrm{C}$. The substrate was used as the working electrode; and the counter electrodes are platinum foil and saturated calomel electrode (SCE), respectively. A luggin capillary was connected to SCE electrode, and the capillary tip was placed very close to the working electrode surface. The samples were immersed in the Hanks' solution for an hour to create the open circuit potential (OCP) or steady-state potential. The electrochemical impedance spectroscopy (EIS) for the sample (Ti alloys) was tested within the frequency range between $100 \mathrm{kHz}$ and $10 \mathrm{MHz} .10 \mathrm{mV}$ of AC (alternating current) was applied on open circuit potential. Nyquist and Bode plots were obtained from the impedance data for each test. After EIS measurements, the system was permitted to achieve open circuit potential (OCP); then the

Table 1 SBF preparation

\begin{tabular}{lll}
\hline Order & \multicolumn{1}{c}{ Reagent } & Amount, g \\
\hline 1. & $\mathrm{CaCl}_{2}$ & 0.185 \\
2. & $\mathrm{KCl}$ & 0.4 \\
3. & $\mathrm{KH}_{2} \mathrm{PO}_{4}$ & 0.06 \\
4. & $\mathrm{MgCl}_{2} \cdot 6 \mathrm{H}_{2} \mathrm{O}$ & 0.1 \\
5. & $\mathrm{MgSO} \cdot 7 \mathrm{H}_{2} \mathrm{O}$ & 0.1 \\
6. & $\mathrm{NaCl}_{2}$ & 8 \\
7. & $\mathrm{NaHCO}_{3}$ & 0.35 \\
8. & $\mathrm{Na}_{2} \mathrm{HPO}_{4}$ & 0.48 \\
9 & $\mathrm{D}-\mathrm{Glucose}$ & 1 \\
\hline
\end{tabular}


electrode was linearly polarized from an initial potential of $200 \mathrm{mV}$ below the OCP value to $200 \mathrm{mV}$ on the positive side at one $\mathrm{mV} / \mathrm{s}$ of scan rate. The measured current and potential data were used to plot Tafel plots. Tafel plots are drawn between potential and log (i) plot. Therefore, with the help of the Tafel plot, $E_{\text {corr }}$-(the corrosion potential) and $I_{\text {corr }}$ (the corrosion current) were concluded. Stern-Geary equation (Ref $26,27)$ is used to determine corrosion current.

$I_{\text {corr }}=(\beta a \times \beta c) / 2.3 \operatorname{Rp}(\beta a+\beta c)$

where $\beta a$ and $\beta c$-slopes of the anodic and cathodic parts of the Tafel Plot, $R_{\mathrm{p}}$-polarization resistance.

\section{Results and Discussion}

\subsection{Raman Analysis}

The DCC is the combination of $\mathrm{sp}^{3}$ and $\mathrm{sp}^{2}$ hybridized bonds. The tribological outcome of DCC coating combination strongly depends on a function of bonding ratio, i.e., $\mathrm{sp}^{2} / \mathrm{sp}^{3}$. This bonding ratio is characterized using Raman spectroscopy in which relative peaks of $D$ and $G$ of $\mathrm{I}_{\mathrm{D}} / \mathrm{I}_{\mathrm{G}}$ play a vital role in Raman studies (Ref 28, 29). Thus, in determining the quality of diamond carbon-coated surface, the bonding ratio $\left(\mathrm{sp}^{3} / \mathrm{sp}^{2}\right)$ is considered to be the predominant factor. The Raman spectra were recorded in the wave number ranging from 1000 to $1800 \mathrm{~cm}^{-1}$. Micro-Raman spectra of DCC coatings consist of disorder $(D)$ and graphite $(G)$ peaks. From Fig. 1 the peak at $1319 \mathrm{~cm}^{-1}$ is attributed to diamond and peak at $1476 \mathrm{~cm}^{-1}$ belongs to single graphite. The $G$ band centered around 1450$1700 \mathrm{~cm}^{-1}$ which relates to $\mathrm{sp}^{2}$ characteristics of graphite-like materials. On the other hand, $D$ band centered around 1200$1400 \mathrm{~cm}^{-1}$ relates to $\mathrm{sp}^{2}$ graphite bond angle disorder which may occur due to breathing mode of $\mathrm{a} \mathrm{sp}^{3}$ carbon atom, and also the crystalline size in $\mathrm{sp}^{2}$ domains (Ref 30 ).

The intensity ratio of $D$ and $G\left(\mathrm{I}_{\mathrm{D}} / \mathrm{I}_{\mathrm{G}}\right)$ is a parameter of relative quantities of $\mathrm{sp}^{3} / \mathrm{sp}^{2}$ bonds. The intensity ratio $I_{\mathrm{D}} / I_{\mathrm{G}}$ was calculated, and it was found to be 1.397 for diamond carbon-coated Ti-13Nb-13Zr alloy and 1.131 for diamond carbon-coated Ti-6Al-4V alloy. These results demonstrate that

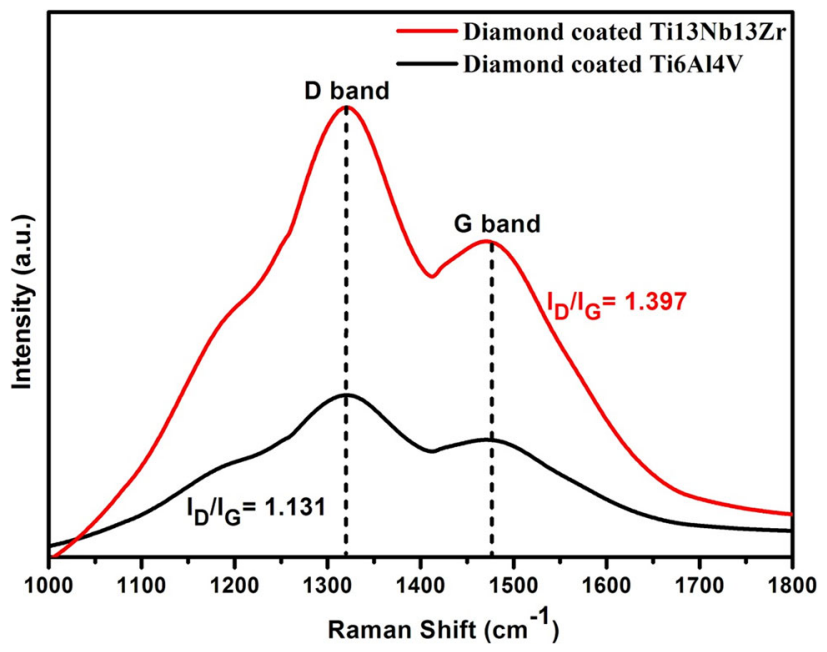

Fig. 1 Raman spectra of diamond carbon-coated Ti-6Al-4V and Ti$13 \mathrm{Nb}-13 \mathrm{Zr}$ substrates the intensity ratio of the $\mathrm{Ti}-13 \mathrm{Nb}-13 \mathrm{Zr}$ alloy is higher than that of Ti-6Al-4V. Increased $I_{D} / I_{G}$ ratio is due to the increased amount of $\mathrm{sp}^{3}$ bond in the coated substrate (Ref 30$)$. Thus, the surface becomes smoother when an exchange of graphite film frames on the counter surface. The smaller increase in the $\mathrm{I}_{\mathrm{D}} / \mathrm{I}_{\mathrm{G}}$ ratio enhances the graphitization of the coated material. Hence, the surface becomes smoother when a transfer of graphite film forms on the counter surface.

\subsection{Surface Morphology}

The FESEM image of diamond carbon-coated Ti-6Al-4V and $\mathrm{Ti}-13 \mathrm{Nb}-13 \mathrm{Zr}$ substrates is shown in Fig. 2. From the FESEM micrograph, continuous and well-faceted diamond carbon crystals are identified. The calculated particle sizes of the DCC on the Ti-6Al-4V and Ti-13Nb-13Zr alloys are $\sim 250$ and $\sim 80 \mathrm{~nm}$, respectively. The larger grain size of the Ti$13 \mathrm{Nb}-13 \mathrm{Zr}$ alloy was attributed to the great seeding of diamond on the $\beta$ phase. The enhanced subsequent growth of diamond on the $\beta$ phase Ti-13Nb-13Zr metal results in bulk grain size. However, $\alpha-\beta$ titanium alloy has a different atom arrangement in the crystal plane such as hcc $(\alpha)$ and bcc $(\beta)$ structure. The nucleation rate of the diamond carbon-coated $\alpha-\beta$ titanium alloy is very less, and hence, the growth factor is predicted to be hidden (Ref 31).

Atomic force microscopy (AFM) was used to analyze the surface topography of the diamond carbon-coated titanium alloys (Ti-6Al-4V and Ti-13Nb-13Zr), and the images are shown in Fig. 3. It is observed from the analysis that the DCCcoated Ti-6Al-4V alloy showed an estimated surface roughness (Ra) of $157 \mathrm{~nm}$ and root mean square (RMS) value of $598 \mathrm{~nm}$. Similarly, DCC Ti-13Nb-13Zr alloy showed the Ra and RMS as $136 \mathrm{~nm}$ and $1114 \mathrm{~nm}$, respectively. The surface roughness value of the diamond carbon-coated near- $\beta$ titanium alloy is superior to that of the $\alpha-\beta$ titanium alloy. Hence, the larger grain size is assigned to diamond carbon-coated near- $\beta$ titanium alloy (Ref 32).

Figure 4 shows the microhardness of the coated and uncoated titanium alloys samples (Ti-6Al-4V and Ti-13Nb$13 \mathrm{Zr})$ at different applied loads (500, 1000, 1500 and $2000 \mathrm{gf})$. It is noticed that the diamond carbon-coated Ti-6Al-4V and Ti$13 \mathrm{Nb}-13 \mathrm{Zr}$ alloys showed greater hardness when compared to uncoated alloys (Ti-6Al-4V and Ti-13Nb-13Zr). The surface hardness of diamond carbon-coated $\mathrm{Ti}-13 \mathrm{Nb}-13 \mathrm{Zr}$ alloys is found to be relatively higher when compared to the Ti-6Al-4V alloy. It is clear that the hardness of DCC titanium alloys depends on the crystallinity and coating thickness (Ref 33). The increase in hardness of DCC near $\beta$ titanium alloys enhances the wear properties of the implants.

\subsection{In vitro Electrochemical Studies}

To understand the corrosion behavior of diamond carbon coatings over Ti-6Al-4V and Ti-13Nb-13Zr, electrochemical studies were conducted. The potentiodynamic polarization curves obtained for the bare substrates and diamond carboncoated substrates in simulated body fluids solution (SBF) are presented in Fig. 5. Using Eq. 1, the corrosion current $\left(I_{\text {corr }}\right)$ density obtained by extrapolating the cathodic and anodic branches of polarization curves (Ref 34). Table 2 gives the corrosion current densities and corrosion potential $\left(E_{\text {corr }}\right)$ for different substrates used in the present study. The corrosion current density $\left(I_{\text {corr }}\right)$ is $4.5 \times 10^{-8} \mu \mathrm{A} / \mathrm{cm}^{2}$ for the Ti-6Al-4V substrate and $7.41 \times 10^{-9} \mu \mathrm{A} / \mathrm{cm}^{2}$ for diamond carbon-de- 

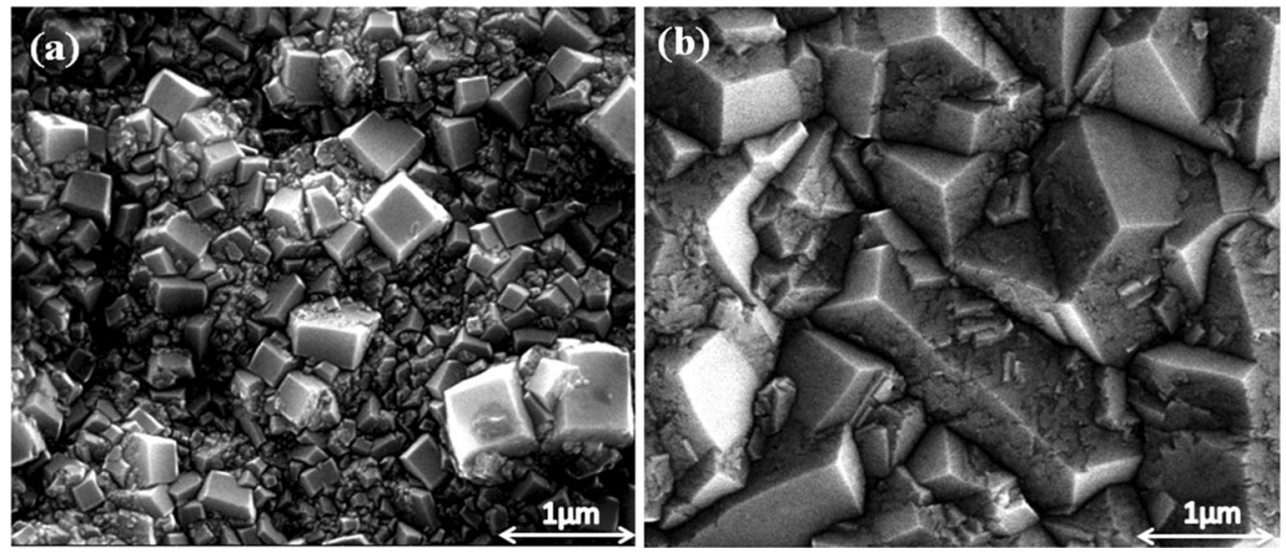

Fig. 2 SEM images of diamond carbon-coated metal alloys (a) Ti-6Al-4V and (b) Ti-13Nb-13Zr

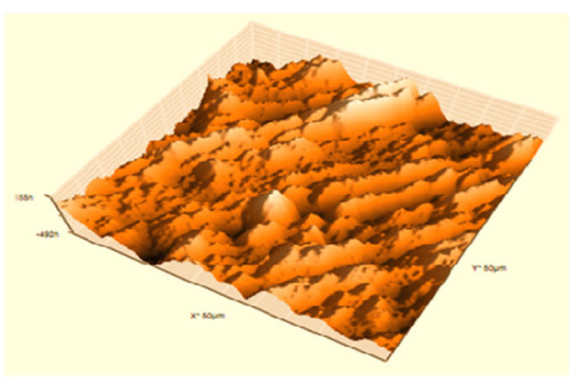

(a)

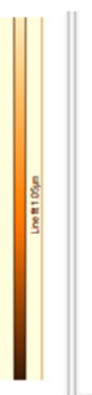

(b)

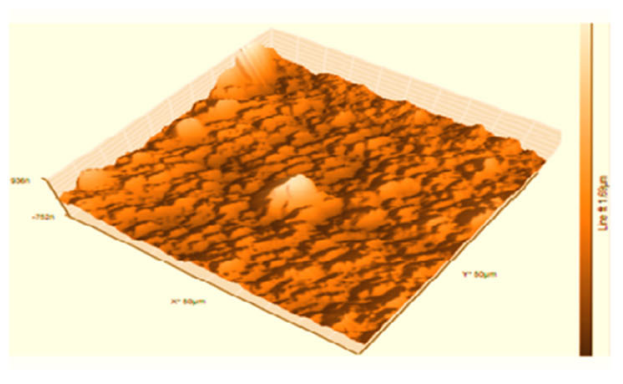

Fig. 3 Surface topography obtained from AFM for diamond carbon-coated alloys (a) Ti-6Al-4V and (b) Ti-13Nb-13Zr

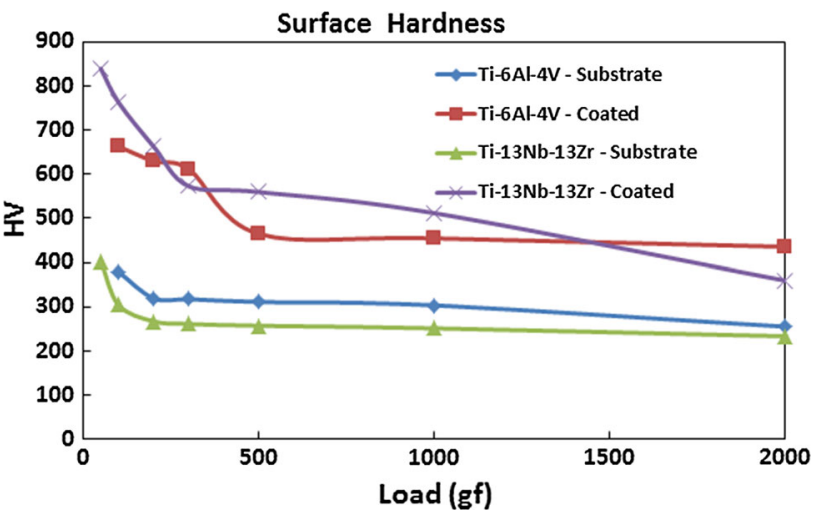

Fig. 4 Microhardness of diamond carbon-coated and uncoated titanium (Ti-6Al-4V and Ti-13Nb-13Zr) alloys

posited Ti-6Al-4V. The corrosion current density is $3.09 \times 10^{-8} \mu \mathrm{A} / \mathrm{cm}^{2}$ for $\mathrm{Ti}-13 \mathrm{Nb}-13 \mathrm{Zr}$ substrate and $3.80 \times 10^{-9} \mu \mathrm{A} / \mathrm{cm}^{2}$ for DCC Ti-13Nb-13Zr alloy. Hence, the corrosion resistance of the substrates increased gradually after surface modification.

The $E_{\text {corr }}$ value of diamond carbon-coated Ti-6Al-4V alloys tends to active region with the value of $-0.168 \mathrm{~V}$ compared to bare substrate $-0.057 \mathrm{~V}$. On the other hand, diamond carboncoated $\mathrm{Ti}-13 \mathrm{Nb}-13 \mathrm{Zr}$ showed more noble value $(-0.210 \mathrm{~V})$ when compared to bare substrate $(-0.273 \mathrm{~V})$. This behavior could be due to the difference in formation of coating on different substrate materials. The results of electrochemical impedance test in Hanks' solution are presented Fig. 6(a) and

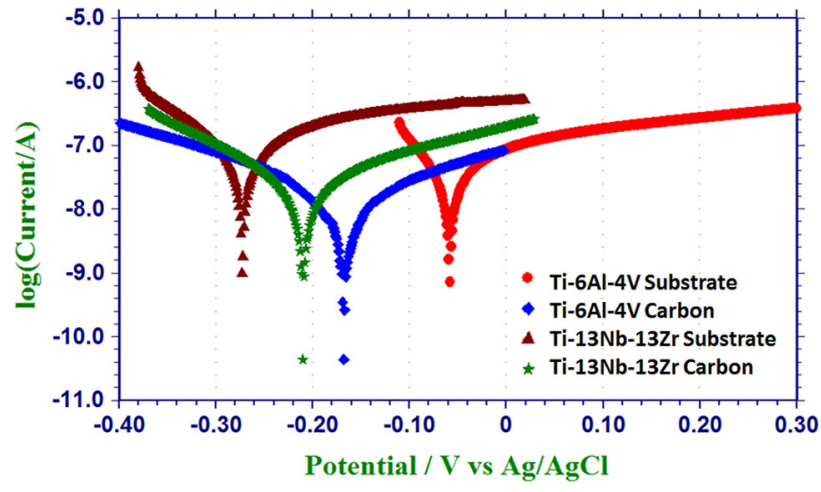

Fig. 5 Potentiodynamic polarization curves for diamond carboncoated and uncoated titanium (Ti-6Al-4V and Ti-13Nb-13Zr) alloys

(b) in the form of Bode plots and Fig. 6(c) in the form of Nyquist plots. For Ti-6Al-4V substrate (see Fig. 6a), the phase angle changes from $-25^{\circ}$ to $-10^{\circ}$ in high frequency range $(10-100 \mathrm{kHz})$. At low frequency range from 0.1 to $100 \mathrm{~Hz}$, the phase angle around $-78^{\circ}$ was remained as nearly constant $\left(<-90^{\circ}\right)$ which is valuable for an ideal capacitor. At $0.1-$ $0.01 \mathrm{~Hz}$ (very low frequencies), the phase angle gradually changed to $-60^{\circ}$. On the other hand, for Ti-13Nb-13Zr substrate [see Fig. 6(a)], the phase angle varies rapidly between $-40^{\circ}$ and $-10^{\circ}$ in the frequency range from 10 to $100 \mathrm{kHz}$. At low frequency range between 0.01 and $100 \mathrm{~Hz}$, the phase angle around $-82^{\circ}$ was remained as nearly constant. A linear relationship for $\log |z|$ and $\log f$ is obtained with a slope close to 
Table 2 Potentiodynamic polarization results of substrate and coated samples

\begin{tabular}{llll}
\hline S. no & \multicolumn{1}{c}{ Sample } & $\boldsymbol{E}_{\mathbf{c o r r}}, \mathbf{V}$ & $\boldsymbol{I}_{\text {corr }}, \boldsymbol{\mu A} / \mathbf{c m}^{2}$ \\
\hline 1. & Ti-6Al-4V substrate & -0.057 & $4.57 \times 10^{-8}$ \\
2. & Ti-6Al-4V diamond carbon-coated & -0.168 & $7.41 \times 10^{-9}$ \\
3. & Ti-13Nb-13Zr substrate & -0.273 & $3.09 \times 10^{-8}$ \\
4. & Ti-13Nb-13Zr diamond carbon-coated & -0.210 & $3.80 \times 10^{-9}$ \\
\hline
\end{tabular}
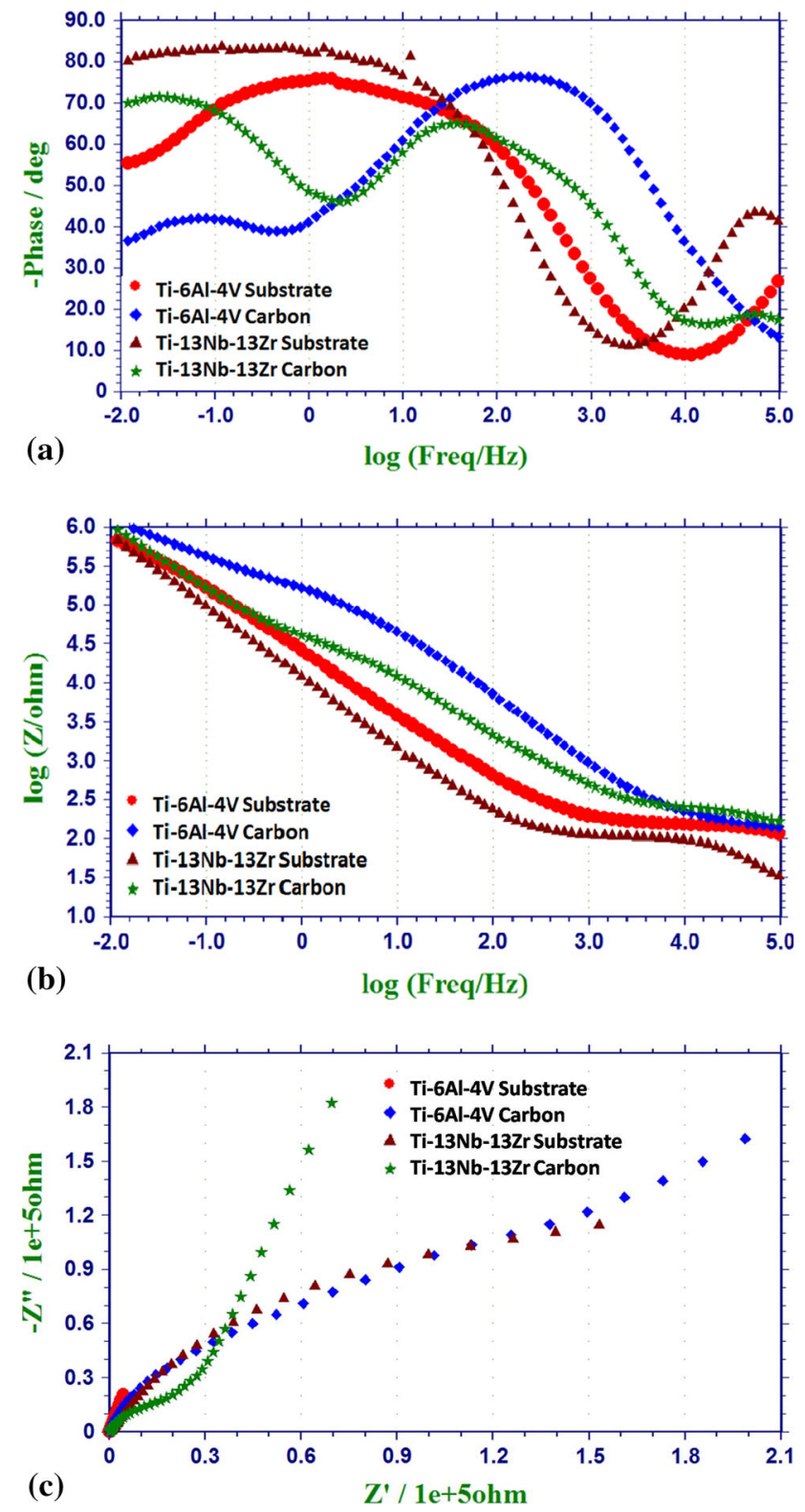

Fig. 6 Bode plots obtained in Hanks' solution: (a) phase, (b) magnitude and (c) Nyquist plots of coated and uncoated substrates

one in the same frequency range in Fig. 6(b). In Fig. 6(a), for Ti-6Al-4V diamond carbon-coated samples, the phase angle rapidly changes from $-10^{\circ}$ to $-75^{\circ}$ in the high frequency range $(100 \mathrm{~Hz}$ to $100 \mathrm{kHz})$. Between 100 and $1 \mathrm{~Hz}$ frequency range, a sudden fall in the phase angle to $-40^{\circ}$ is noticed. In the case of $\mathrm{Ti}-13 \mathrm{Nb}-13 \mathrm{Zr}$ diamond carbon-coated samples, the phase angle changes from $-20^{\circ}$ to $-60^{\circ}$ in the high frequency range $(100 \mathrm{~Hz}$ to $100 \mathrm{kHz})$. Between 100 and

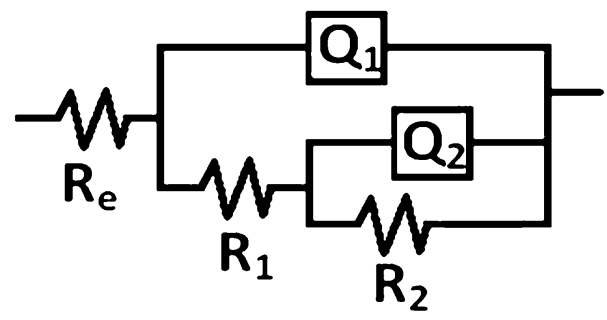

Fig. 7 Equivalent circuit (EC) diagram used for fitting EIS data of the substrate and diamond carbon-coated samples

$1 \mathrm{~Hz}$ frequency range, a sudden fall in the phase angle to $-40^{\circ}$ is noticed. In the very low frequency range between 1 and $0.01 \mathrm{~Hz}$, the phase angle increases rapidly to $-70^{\circ}$. The Nyquist plots of DCC samples in Fig. 6(c) showed a larger diameter at higher frequencies when compared to uncoated substrates.

The electrochemical equivalent circuit (EEC) model which is used to fit the EIS (electrochemical impedance spectroscopy) data for pure DCC substrate and uncoated substrate as shown in Fig. 7. The EEC consists of resistances and CPE (constant phase element). This CPE is used to change in the relaxation times as a result of different degrees of surface inhomogeneity. The impedance with the capacitance can be defined as $Z_{\mathrm{CPE}}=\left[Q\left(j \omega^{n}\right)\right]^{-1}$, where $Q, j, \omega$ and $n$ are the pseudocapacitance or non-ideal capacitance, imaginary function $(\sqrt{ }-1)$, angular frequency and the deviation from the ideal behavior of a pure capacitor, respectively. When $n=1$, the system behaves like a pure capacitor and $Q=C$, where $C$ is capacitance (Ref 35,36 ). In the EEC the resistive component $R_{\mathrm{S}}$ represents the solution resistance. $R_{1}$ and $R_{2}$ represent outer and inner layer resistances, respectively. $Q_{1}$ and $Q_{2}$ represent the capacitance of the outer layer and inner layer, respectively. The parameters $Q_{1}$ and $R_{1}$ represent properties of the porous film/solution interface, i.e., the charge transfer resistance and double layer capacitance. Table 3 gives the electrical parameter values obtained by fitting the EIS data for the substrate and DCC-coated samples. From Table 3, uncoated substrate (Ti$6 \mathrm{Al}-4 \mathrm{~V}$ and $\mathrm{Ti}-13 \mathrm{Nb}-13 \mathrm{Zr}$ ) of the inner oxide layer corrosion resistance $R_{2}$ is $2.77 \times 10^{6}$ and $6.98 \times 10^{6} \Omega \mathrm{cm}^{2}$, respectively. The substrate (Ti-6Al-4VTi-6Al-4V and Ti-13Nb-13Zr) outer porous layer resistance is 106 and $90 \Omega \mathrm{cm}^{2}$, respectively. The CPE value of $n_{1}$ outer layer substrate is 0.78 and 0.93 (Ti-6Al$4 \mathrm{~V}$ and $\mathrm{Ti}-13 \mathrm{Nb}-13 \mathrm{Zr}$ ), and the inner layer $\mathrm{n}_{2}$ substrate is 0.91 and 0.90 (Ti-6Al-4V and Ti-13Nb-13Zr). The non-ideal value for the CPE value of $n_{1}$ outer layer DCC is 0.78 and 0.73 (Ti$6 \mathrm{Al}-4 \mathrm{~V}$ and Ti-13Nb-13Zr), and inner layer $n_{2} \mathrm{DCC}$ is 0.90 and 0.92 (Ti-6Al-4V and $\mathrm{Ti}-13 \mathrm{Nb}-13 \mathrm{Zr}$ ) which is very close to unity when compared to the uncoated titanium alloys. The results indicate that protection provided by passive layer is predominately due to the barrier layer (Ref 36). Hence, the diamond carbon-coated titanium alloys are observed to be a 
Table 3 Equivalent circuit parameters obtained by fitting the electrochemical impedance data for substrates and diamond coated samples

\begin{tabular}{|c|c|c|c|c|c|c|c|c|}
\hline Sample & $\operatorname{Re}, \Omega \mathrm{cm}^{2}$ & $Q_{1} S s^{n}, 1 / \mathrm{cm}^{2}$ & $n_{1}$ & $R_{1}, \Omega \mathrm{cm}^{2}$ & $\mathrm{Q} 2 \mathrm{~S} \mathrm{~s}{ }^{\mathrm{n},} 1 / \mathrm{cm}^{2}$ & $n_{2}$ & $\mathrm{R}_{2}, \Omega \mathrm{cm}^{2}$ & $\chi^{2}$ \\
\hline Ti-6Al-4V substrate & 14 & $2.62 \times 10^{-6}$ & 0.78 & 106 & $5.95 \times 10^{-6}$ & 0.91 & $2.77 \times 10^{6}$ & $8.7 \times 10^{-4}$ \\
\hline Ti-6Al-4V diamond carbon-coated & 15 & $5.35 \times 10^{-7}$ & 0.78 & $1.49 \times 10^{5}$ & $3.38 \times 10^{-6}$ & 0.90 & $3.56 \times 10^{6}$ & $5.6 \times 10^{-4}$ \\
\hline Ti-13Nb-13Zr substrate & 16 & $1.60 \times 10^{-5}$ & 0.93 & 90 & $1.67 \times 10^{-7}$ & 0.90 & $6.98 \times 10^{6}$ & $3.6 \times 10^{-4}$ \\
\hline Ti-13Nb-13Zr diamond carbon-coated & 20 & $4.70 \times 10^{-6}$ & 0.73 & $3.31 \times 10^{5}$ & $1.14 \times 10^{-6}$ & 0.92 & $9.42 \times 10^{6}$ & $1.8 \times 10^{-3}$ \\
\hline
\end{tabular}

good choice due to its better electrochemical reactions, enhanced surface hardness and corrosion resistance properties.

\section{Conclusion}

Diamond carbon has been deposited on Ti-13Nb-13Zr and Ti-6Al-4V biomedical alloy by HFCVD method. The FESEM results show that diamond carbon-coated Ti-13Nb-13Zr particle size is greater than the diamond carbon-coated Ti-6Al-4V sample. Raman studies confirmed the formation of diamond carbon crystal coatings. The surface hardness of the diamond carbon-coated $\mathrm{Ti}-13 \mathrm{Nb}-13 \mathrm{Zr}$ alloy is higher than the diamond carbon-coated Ti-6Al-4 V alloy, which leads to improved mechanical properties of the implants. Potentiodynamic polarization studies showed that the corrosion resistance of diamond carbon-coated Ti-13Nb-13Zr alloy is better than the bare Ti6Al-4V. Electrochemical impedance studies in SBF solution showed that diamond carbon-coated samples behave like a near-ideal capacitor with better passivation behavior than the bare substrates. The polarization resistance and corrosion current density of the diamond carbon-coated $\mathrm{Ti}-13 \mathrm{Nb}-13 \mathrm{Zr}$ alloy is relatively higher when compared to the diamond carbon-coated Ti-6Al-4V substrate. Hence, diamond carboncoated $\mathrm{Ti}-13 \mathrm{Nb}-13 \mathrm{Zr}$ alloy helps in improving the corrosion and mechanical properties. Therefore, diamond carbon-coated near- $\beta$ titanium alloy provides higher corrosion protection and also offers good mechanical properties than that of the diamond carbon-coated Ti-6Al-4V alloy, which can be used for biomedical implant applications.

\section{References}

1. S. Kurtz, Projection of Primary and Revision Hip and Knee Arthoroplasty in Unites State from 2005 to 2030, J. Bone Jt. Surg., 2007, 89, p 780-785

2. S.M. Kurtz, E. Lau, K. Ong, K. Zhao, M. Kelly, and K.J. Bozic, Future Young Patient Demand for Primary and Revision Joint Replacement: National Projections from 2010 to 2030, Clin. Orthop. Relat. Res., 2009, 467, p 2606-2612

3. M. Geetha, A.K. Singh, R. Asokamani, and A.K. Gogia, Ti Based Biomaterials, the Ultimate Choice for Orthopedic Implants, Prog. Mater. Sci., 2009, 54, p 397-425

4. M. Long and H.J. Rack, Titanium Alloys in Total Joint Replacement-A Materials Science Perspective, Biomaterials, 1998, 19, p $1621-1639$

5. Y. Abu-Amer, I. Darwech, and J.C. Clohisy, Aseptic Loosening of Total Joint Replacements: Mechanisms Underlying Osteolysis and Potential Therapies, Arthritis Res. Ther., 2007, 9, p S6

6. R. Pareta, L. Yang, A. Kothari, S. Sirinrath, X. Xiao, B.W. Sheldon et al., Tailoring Nanocrystalline Diamond Coated on Titanium for Osteoblast Adhesion, J. Biomed. Mater. Res. Part A, 2010, 95, p 129 136
7. Y. Yan, A. Neville, and D. Dowson, Bio Tribocorrosion of Co Cr Mo Orthopedic Implant Materials-Assessing the Formation and Effect of the Biofilm, Tribol. Int., 2007, 40, p 1492-1499

8. R. Hauert, Tribology of Diamond-like Carbon Films: Fundamentals and Applications, ed by C. Donnet, A. Erdemir (Springer, New York, 2008) pp. 494-509

9. X. Liu, P.K. Chu, and C. Ding, Surface Nano-functionalization of Biomaterials, Mater. Sci. Eng., 2010, 70(3-6), p 275-302

10. V. Gopal, M. Chandran, and M.S. Ramachandra, Tribocorrosion and Electrochemical Behaviour of Nanocrystalline Diamond Coated Ti Based Alloys for Orthopaedic Application, Tribol. Int., 2017, 106, p $88-100$

11. S.P. Patterson, R.H. Daffner, and R.A. Gallo, Electrochemical Corrosion of Metal Implants, AJR Am. J. Roentgenol., 2005, 184, p 1219-1222

12. S.R. Paital and N.B. Dahotre, Calcium Phosphate Coatings for Bioimplant Applications: Materials, Performance Factors, and Methodologies, Mater. Sci. Eng., 2009, 66, p 1-3

13. M. Spector, Biomaterial Failure, Orthop. Clin., 1992, 23, p 211-217

14. M. Kaczmare, M.U. Jurczyk, A. Miklaszewski, A. Paszel-Jaworska et al., In Vitro Biocompatibility of Titanium After Plasma Surface Alloying with Boron, Mater. Sci. Eng. C, 2016, 69, p 1240-1247

15. R. Hauert, A Review of Modified DLC Coatings for Biological Applications, Diamond Relat. Mater., 2003, 12, p 583-589

16. A. Grill, Tribology of Diamond Like Carbon and Related Materials: An Updated Review, Surf. Coat. Technol., 1997, 94, p 507-513

17. P. Yang, S.C.H. Kwok, P.K. Chu, Y.X. Leng, J.Y. Chen, J. Wang, and N. Huang, Haemocompatibility of Hydrogenated Amorphous Carbon (a-C:H) Films Synthesized by Plasma Immersion Ion ImplantationDeposition, Nucl. Instrum. Methods Phys. Res. Sect. B, 2003, 206, p 721-725

18. L.J. Yu, X. Wang, X.H. Wang, and X.H. Liu, Heamo Compatibility of Tetrahedral Amorphous Carbon Film, Surf. Coat. Technol., 2000, 128(129), p 484-488

19. N. Urdin, P. Francois, M. Moret, K. Unal, J. Krumeich, B.O. Aronsson, and P. Descounts, Hemocompatible Diamond-Like Carbon (DLC) Surfaces, Eur. Cells Mater., 2003, 5, p 17-28

20. M.I. Jones, I.R. McColl, D.M. Grant, K.G. Parker, and T.L. Parker, Haemocompatibility of DLC and TiC-TiN Interlayers on Titanium, Diamond Relat. Mater., 1999, 8(2-5), p 457-462

21. S. Linder, W. Pinkowski, and M. Aepfelbacher, Adhesio Cytoskeletal Architecture and Activation Status of Primary Human Macrophages on a Diamond-Like Carbon Coated Surface, Biomaterials, 2002, 23, p 767-773

22. K. Al Mahmud, M. Varman, M. Kalam, H. Masjuki, H. Mobarak, and N. Zulkifli, Tribological Characteristics of Amorphous Hydrogenated $(\mathrm{aC}: \mathrm{H})$ and Tetrahedral (ta-C) Diamond-Like Carbon Coating at Different Test Temperatures in the Presence of Commercial Lubricating Oil, Surf. Coat. Technol., 2014, 245, p 133-147

23. M. Mohanty, T.V. Anilkumar, P.V. Mohanan, C.V. Muraleedharan, G.S. Bhuvaneshwar, F. Derangere, Y. Sampeur, and R. Suryanarayanan, Long Term Tissue Response to Titanium Coated with Diamond Like Carbon, Biomol. Eng., 2002, 19, p 125-128

24. D. Sheeja, B.K. Tay, and L.N. Nung, Feasibility of Diamond-Like Carbon Coatings for Orthopedic Applications, Diamond Relat. Mater., 2004, 13(1), p 184-190

25. S.H. Din, M.A. Shah, and N.A. Sheikh, Effect of CVD-Diamond on the Tribological and Mechanical Performance of Titanium Alloy (Ti6Al4V), Tribol. Ind., 2016, 38(4), p 530-542

26. L. Mohan, P. Dillibabu, P. Kmar, and C. Anandan, Influence of Zirconium Doping on the Growth of Apatite and Corrosion Behavior 
of DLC-Coated Titanium Alloy Ti-13Nb-13Zr, Surf. Interface Anal. 2013, 45(11-12), p 1785-1791

27. V. Baranauskas, H.J. Ceragioli, A.C. Peterlevitz, and M. Fontana, Low Residual Stress Diamond Coatings on Titanium, Surf. Coat. Technol., 2005, 200, p 2343-2347

28. S. Ghosh, D. Choudhury, T. Roy, A.B. Mama, H.H. Masjuki, and B. Pingguan-Murphy, Tribological Investigation of Diamond Like Carbon Coated Micro-dimpled Surface Under Bovine Serum and Osteoarthritis Oriented Synovial Fluid, Sci. Technol. Adv. Mater., 2015, 16, p 3

29. S. Tamilselvi, V. Raman, and N. Rajendran, Electrochemical Impedance Spectroscopic Characterization of Titanium During Alkali Treatment and Apatite Growth in Simulated Body Fluid, Electrochem. Acta, 2007, 52, p 7418-7424

30. T. Falcade, T.E. Shimitzhauz, O.G. dos Reisb et al., Electrodeposition of Diamond-Like Carbon Films on Titanium Alloy Using Organic Liquids: Corrosion and Wear Resistance, Appl. Surf. Sci., 2012, 263, p $18-24$
31. T.J. Dines, D. Tither, A. Dehbi, and A. Mathews, Raman Spectra of Hard Carbon Films and Hard Carbon Films Containing Secondary Elements, Carbon, 1991, 29, p 225-231

32. D. Durgalakshmi and M. Chandran, Studies on Corrosion and Wear Behavior of Sub Micrometric Diamond Coated Ti Alloys, Tribol. Int., 2013, 63, p 132-140

33. B. Ramamoorthy, B.C. Yelldose, and Scires, An Investigation into the Adhesion Strength of Diamond Like Carbon Multilayer Coating (DLC/ TiN/Ti/Cu/Ni), IIM Int., 2009, 1, p 179-194

34. C. Anandan and L. Mohan, Wear and Corrosion Behavior of Oxygen Implanted Biomedical Titanium Alloy Ti-13Nb-13Zr, Appl. Surf. Sci., 2013, 282, p 281-290

35. M. Metikos-Hukovic and R. Babic, Passivation and Corrosion Behaviours of Cobalt and Cobalt-Chromium-Molybdenum Alloy, Corros. Sci., 2007, 40, p 3570-3579

36. I. Milosev, T. Kosec, and H.H. Strehblow, XPS and EIS Study of the Passive Film Formed on Orthopaedic Ti-6Al-7Nb Alloy in Hank's Physiological Solution, Electrochim. Acta, 2008, 53, p 3547-3558 